\title{
Joint SNMMI and EANM guideline for small-bowel and colon transit: an important step towards long-awaited standardization
}

\author{
Giuliano Mariani • Italia Paglianiti
}

Published online: 17 January 2014

(C) EANM 2013

The recent publication in the Journal of Nuclear Medicine of the joint SNMMI and EANM practice guideline for smallbowel and colon transit [1] follows the new strategy that the two societies have adopted with the praiseworthy goal of standardizing and harmonizing the practice of nuclear medicine across nations. This was initiated about 2 years ago with a master document describing the methodology (or, preliminarily, guideline) for the two societies to develop joint practice guidelines [2]. Soon afterwards, groups of experts designated by the two societies jointly started to develop up-to-date practice guidelines for nuclear medicine procedures at the cutting edge of the discipline on the use of $\left[{ }^{18} \mathrm{~F}\right] \mathrm{FDG}$ for imaging inflammation and infection [3], on peptide receptor radionuclide therapy [4], and on radioguided sentinel lymph node biopsy in patients with breast cancer [5]. Work is also in progress to define joint practice guidelines for other nuclear medicine procedures as well.

In principle, the study of gastrointestinal transit is not a new cutting-edge procedure in nuclear medicine, as these studies have been employed for over 40 years [6, 7]. Therefore, the technique should no longer be considered in the early phases of clinical application, when protocols vary in several respects among different centres, not unlike what is observed today in the imaging field when a new method is introduced; variable acquisition and processing protocols for magnetic resonance imaging fit well with this notion [8]. Nevertheless, radionuclide gastrointestinal transit studies (in relation especially to small-bowel and colon transit) still suffer from a considerable degree of heterogeneity among different nuclear medicine centres concerning important practical aspects not only of the procedure itself (such as, for example, preparation and

\footnotetext{
G. Mariani $(\bowtie) \cdot$ I. Paglianiti

Regional Center of Nuclear Medicine, University of Pisa,

Via Roma 67, 56126 Pisa, Italy

e-mail: giuliano.mariani@med.unipi.it
}

composition of the radiolabelled meal, acquisition modalities, and semiquantitative assessment of the data obtained), but also in the way the results are reported. This heterogeneity is due at least in part to different availabilities among different countries of standardized basic components of a radiolabelled meal (e.g. the commercial generally used egg white preparation available only in the US). Other sources of heterogeneity stem from country-specific variations in the balance of the basic nutrients (i.e. carbohydrates, proteins, fats), and in variable palatability in different cultures in relation to food composition.

On the other hand, it should not be disregarded that, from the nuclear medicine point of view, gastrointestinal transit studies constitute in general a "niche" activity with a limited number of procedures when compared with most radionuclide imaging procedures commonly performed in any nuclear medicine centre. In fact, there are some alternative nonradionuclide procedures that the specialist in gastroenterology can use in his/her own environment (chiefly based on the breath test principle, and more recently on the use of wireless motility capsules) to obtain seemingly the same diagnostic information as that derived from a classical radionuclide gastrointestinal transit studies; however, there is no perfect correspondence between nonradionuclide and radionuclide-based investigation modalities, with the latter mirroring as closely as possible the true physiology of gastrointestinal motility [9-15]. This scenario favours local variations in protocols introduced to meet specific expectations of the referring specialists, making standardization among different centres difficult.

The joint SNMMI/EANM definition of practice guideline for small-bowel and colon transit scintigraphy is a reflection of the present-day relevance of this type of radionuclide imaging study in current clinical practice. Indeed, assessment of gastrointestinal transit is an important tool for the clinician in the diagnostic approach to (and subsequent treatment of) 
common gastrointestinal disorders, considering that it is often difficult for the clinician to determine whether symptoms are caused by upper and/or lower gastrointestinal tract dysfunction. Despite some limitations linked to a certain lack of standardization [16], that is expected to be overcome with the publication of the practice guideline [1] and several reviews [17-20], radionuclide gastrointestinal transit studies are easy to perform, require only a modest amount of patient cooperation, and entail a quite low radiation burden when compared to alternatives based on radiological imaging of radioopaque markers ingested orally.

Yet it is a common notion that the total number of radionuclide small-bowel and colon transit procedures performed as part of the routine clinical approach to patients with gastrointestinal motility disorders is consistently smaller than the actual clinical need, a possible consequence, at least in some countries, of the lack of a current procedural terminology code and reimbursement for these procedures. Thus, in many instances the approach to investigating gastrointestinal transit times comprises substrate hydrogen breath tests for smallbowel transit and assessment of the progression time of radioopaque markers or wireless motility capsules along the large bowel.

However, indigestible solid particles such as radioopaque markers (4 $\mathrm{mm}$ diameter) and wireless motility capsules (10 mm longest axis) do not move through the gastrointestinal tract in the same manner as a physiological meal, and a radiolabelled meal employed for small-bowel and colonic transit studies can be considered as such [9, 21]. The most physiological approach to measuring gastrointestinal transit time remains imaging normal foods labelled with a small amount of radiotracer; indeed, as stated by a task force committee of the American Motility Society "the scintigraphic method is the only one that reliably allows the determination of both total and regional transit times" for gastrointestinal and colon transit [22]. In this regard, with minor modifications small-bowel and colon transit scintigraphy studies are easily performed as a continuation of a standard gastric emptying study. Nevertheless, assessment of small-bowel transit using an orally administered agent is always complicated by its dependency on gastric emptying. In this regard, an advantage of using a simple water-based radioactive tracer made by adding a suitable nonabsorbable radiolabelled agent is that gastric emptying of liquids is rarely so delayed as to significantly affect small-bowel transit.

The joint SNMMI/EANM practice guideline [1] describes in detail the various single-meal or combination-meal procedures employed for gastrointestinal transit imaging. In particular, three protocol options for gastrointestinal transit imaging have been reported: option A (whole-gut transit study), option B (small-bowel transit study) and option C (colon transit study). In turn, option A is divided into the two methods most commonly adopted worldwide, developed at Temple
University and at Mayo Clinic, respectively. Detailed technical notes on each protocol option are especially useful from the perspective of standardization, as they convey information on specific acquisition parameters (collimator, matrix, energy setting) and timing of imaging for all the options described. Furthermore, the reader is guided through interpretation of the scintigraphic transit study, as the guideline describes in depth all the sufficiently validated methods to define quantitative parameters, such as total abdominal count analysis, smallbowel transit analysis, terminal ileum filling method, colon filling method, and a deconvolution method incorporating gastric emptying and colon filling. In addition, preparation, composition and administration of the radiolabelled meal(s), these are the critical steps that should be carefully considered for standardizing scintigraphic techniques and for harmonizing analysis and reporting of small-bowel and colon transit studies. Finally, the guideline describes the potential sources of error in gastrointestinal transit studies, thus helping the nuclear physician recognize the factors that can cause errors in quantitative analysis.

A further important step towards standardization and harmonization of gastrointestinal transit studies would be the definition of practice guidelines developed jointly not only within the nuclear medicine community (as has been accomplished by the joint effort of the SNMMI and the EANM), but above all between the nuclear medicine community and the gastroenterology community, similar to the recent guidelines for cardiac studies produced jointly by the SNMMI, the American Society of Nuclear Cardiology, and the Society of Cardiovascular CT [23]. We would thus fill the gap represented by the absence of the nuclear medicine community from the overall scenario of gastrointestinal motility disorders, for instance by contributing to the update of the common position paper published some years ago by a joint task force established by the American and European neurogastroenterology and motility societies [24].

\section{References}

1. Maurer AH, Camilleri M, Donohoe K, et al. The SNMMI and EANM practice guideline for small-bowel and colon transit 1.0. J Nucl Med. 2013;54:2004-13.

2. Delbeke D, Chiti A, Christian P, Darcourt J, Donohoe K, Flotats A, et al. SNMMI/EANM guideline for guideline development 6.0. J Nucl Med Technol. 2012;40:283-9.

3. Jamar F, Buscombe J, Chiti A, Christian PE, Delbeke D, Donohoe $\mathrm{KJ}$, et al. EANM/SNMMI guideline for ${ }^{18} \mathrm{~F}-\mathrm{FDG}$ use in inflammation and infection. J Nucl Med. 2013;54:647-58.

4. Zaknun JJ, Bodei L, Mueller-Brand J, Pavel ME, Baum RP, Hörsch $\mathrm{D}$, et al. The joint IAEA, EANM, and SNMMI practical guidance on peptide receptor radionuclide therapy (PRRNT) in neuroendocrine tumours. Eur J Nucl Med Mol Imaging. 2013;40:800-16.

5. Giammarile F, Alazraki N, Aarsvold JN, Audisio RA, Glass E, Grant $\mathrm{SF}$, et al. The EANM and SNMMI practice guideline for 
lymphoscintigraphy and sentinel node localization in breast cancer. Eur J Nucl Med Mol Imaging. 2013;40:1932-47.

6. Holdstock DJ, Misiewicz JJ, Smith T, Rowlands EN. Propulsion (mass movements) in the human colon and its relationship to meals and somatic activity. Gut. 1970;11:91-9.

7. Rinetti M, Ugolotti G, Calbiani B, Colombi-Zinelli L, Cisternino M, Papa N. Antiinflammatory drugs and gastric emptying. A comparison between acetylsalicylic acid and carprofen. Arzneimittelforschung. 1982;32:1561-3.

8. Ashton E, Riek J. Advanced MR techniques in multicenter clinical trials. J Magn Reson Imaging. 2013;37:761-9.

9. Madsen JL, Larsen NE, Hilsted J, Worning H. Scintigraphic determination of gastrointestinal transit times. A comparison with breath hydrogen and radiologic methods. Scand J Gastroenterol. 1991;26: 1263-71.

10. Sciarretta G, Furno A, Mazzoni M, Garagnani B, Malaguti P. Lactulose hydrogen breath test in orocecal transit assessment. Critical evaluation by means of scintigraphic method. Dig Dis Sci. 1994;39:1505-10.

11. Miller MA, Parkman HP, Urbain JL, Brown KL, Donahue DJ, Knight LC, et al. Comparison of scintigraphy and lactulose breath hydrogen test for assessment of orocecal transit: lactulose accelerates small bowel transit. Dig Dis Sci. 1997;42:10-8.

12. Ternent CA, Thorson AG, Blatchford GJ, Christensen MA, Thompson JS, Lanspa SJ, et al. Mouth to pouch transit after restorative proctocolectomy: hydrogen breath analysis correlates with scintigraphy. Am J Gastroenterol. 2001;96:1460-3.

13. Kuo B, McCallum RW, Koch KL, Sitrin MD, Wo JM, Chey WD, et al. Comparison of gastric emptying of a nondigestible capsule to a radio-labelled meal in healthy and gastroparetic subjects. Aliment Pharmacol Ther. 2008;27:186-96.

14. Boillat CS, Gaschen FP, Gaschen L, Stout RW, Hosgood GL. Variability associated with repeated measurements of gastrointestinal tract motility in dogs obtained by use of a wireless motility capsule system and scintigraphy. Am J Vet Res. 2010;71:903-8.

15. Goodman K, Hodges LA, Band J, Stevens HN, Weitschies W, Wilson CG. Assessing gastrointestinal motility and disintegration profiles of magnetic tablets by a novel magnetic imaging device and gamma scintigraphy. Eur J Pharm Biopharm. 2010;74:84-92.

16. Parkmann HP. Scintigraphy for evaluation of patients for GI motility disorders - the referring physician's perspective. Semin Nucl Med. 2012;42:76-8.

17. Mariani G, Boni G, Barreca M, Bellini M, Fattori B, AlSharif A, et al. Radionuclide gastroesophageal motor studies. J Nucl Med. 2004;45: 1004-28.

18. Mariani G, Pauwels EKJ, AlSharif A, Marchi S, Boni G, Barreca M, et al. Radionuclide evaluation of the lower gastrointestinal tract. J Nucl Med. 2008;49:776-87.

19. Odunsi ST, Camilleri M. Selected interventions in nuclear medicine: gastrointestinal motor functions. Semin Nucl Med. 2009;39:186-94.

20. Szarka LA, Camilleri M. Methods for the assessment of small-bowel and colonic transit. Semin Nucl Med. 2012;42:113-23.

21. Southwell BR, Clarke M, Sutcliffe J, Hutson J. Colonic transit studies: normal values for adults and children with comparison of radiological and scintigraphic methods. Pediatr Surg Int. 2009;25: 559-72.

22. Lin HC, Prather C, Fisher R, Meyer JH, Summers RW, Pimentel M, et al. Measurement of gastrointestinal transit: AMS task force committee on gastrointestinal transit. Dig Dis Sci. 2005;50:989-1004.

23. Dorbala S, Di Carli MF, Delbeke D, Abbara S, DePuey EG, Dilsizian $\mathrm{V}$, et al. SNMMI/ASNC/SCCT guideline for cardiac SPECT/CT and PET/CT 1.0. J Nucl Med. 2013;54:1485-507.

24. Rao SS, Camilleri M, Hasler WL, Maurer AH, Parkman HP, Saad R, et al. Evaluation of gastrointestinal transit in clinical practice: position paper of the American and European Neurogastroenterology and Motility Societies. Neurogastroenterol Motil. 2011;23:8-23. 